\title{
Character association in mulberry under different magnitude of salinity stress
}

\author{
K. Vijayan ${ }^{1,4 *}$, S. G. Doss ${ }^{1}$, S. P. Chackraborti ${ }^{1}$, P. D. Ghosh ${ }^{2}$ and \\ B. Saratchandra ${ }^{3}$
}

\begin{abstract}
${ }^{1}$ Central Sericultural Research and Training Institute, Berhampore, West Bengal-742 101, India; ${ }^{2}$ Department of Botany, University of Kalyani, Nadia, West Bengal-741 235, India; ${ }^{3}$ Central silk Board, Madiwala, Bangalore-560068, India; ${ }^{4}$ Institute of Plant and Microbial Biology, Academia Sinica, Taipei, Taiwan-115, ROC
\end{abstract}

\begin{abstract}
Information on interrelationships among traits is important for varietal development. Under stress conditions the magnitude of character association is known to change significantly. In mulberry such information on such aspects is lacking. Hence, the interrelationships of leaf yield and its component morphological, physiological and biochemical traits were investigated under four different salinity conditions using 11 genotypes. Correlation coefficient between leaf yield and its component traits was found changing significantly under different salinity stresses. Under normal condition leaf yield was found significantly and positively correlated with leaf size, root length, shoot length, protein content, and water use efficiency. However, under severe salinity imposed by $1.00 \% \mathrm{NaCl}$, significant correlation was observed with plant height, leaf size, shoot weight, root weight, root length, protein, nitrogen reductase (NRase) activity and water use efficiency (WUE) of the plant. Similarly, relationship of plant height with other traits also changed with increasing salinity. These changes in the interrelationships among the traits point to the need of different selection strategy for breeding varieties under normal and abiotic stress conditions.
\end{abstract}

Keywords: Mulberry, correlation coefficient, salinity, leaf yield.

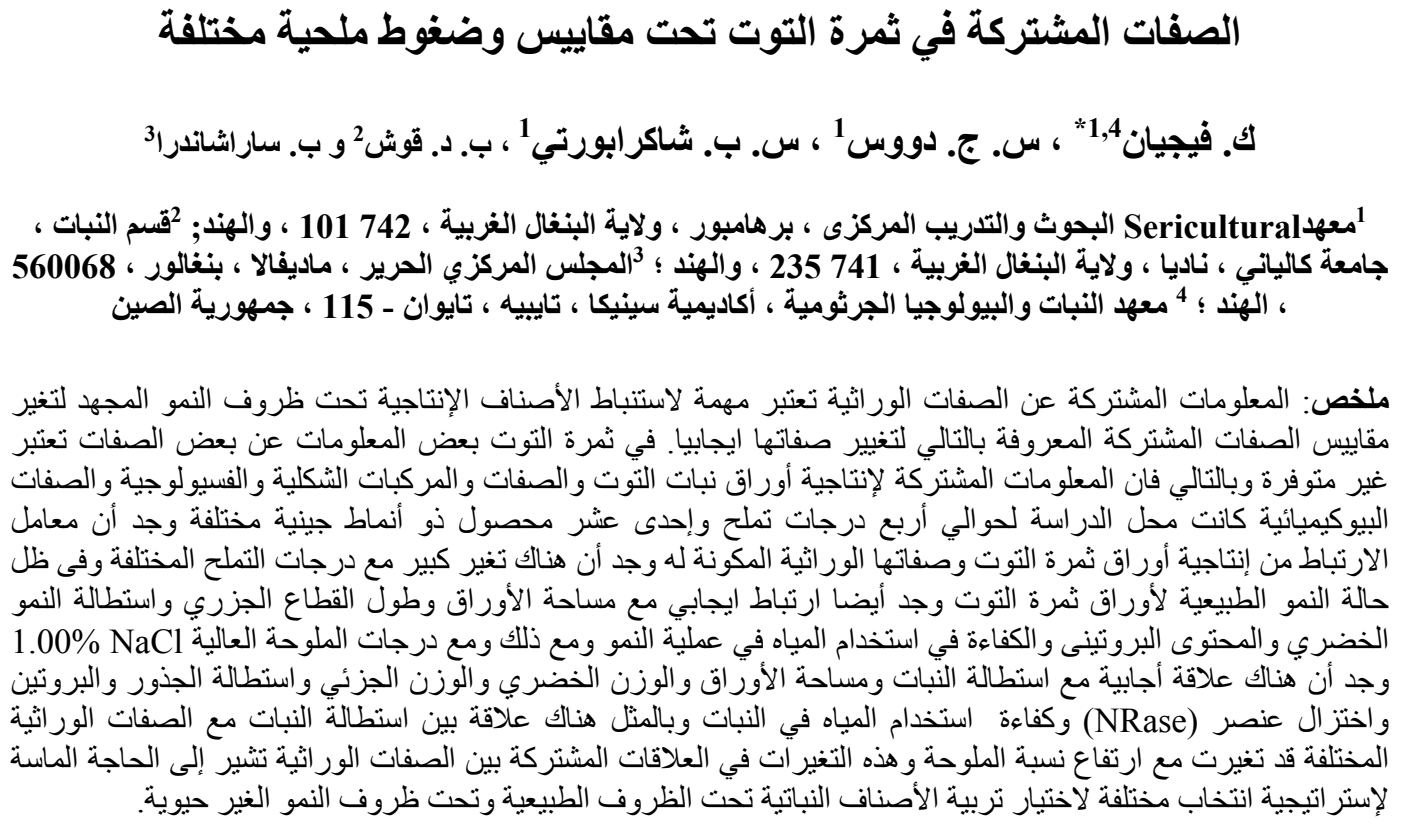

* Corresponding Author, Email: kvijayan01@yahoo.com 


\section{Introduction}

Mulberry (Morus) of the family Moraceae is one of the most valued tree crops in several Asian countries like China, India, Korea, Bangladesh etc. due to its key role in sustaining the sericulture industry and thereby providing employments to a large number of people. Mulberry leaf is the only feed available for the silkworm Bombyx mori, hence, availability of good quality leaf has great impact on the sustainability and profitability of sericulture. Keeping this in view, breeding in mulberry mainly targets on developing varieties that grow well under divergent agro-climatic conditions to produce higher quantity of qualitatively superior leaf (Vijayan et al., 2008a, Vijayan, 2009). Leaf yield in mulberry is a complex trait contributed by many components such as plant height, number of branches, leaf retention capacity, nodal length and leaf weight (Banerjee et al., 2007; Sahu et al., 1995; Tikader and Kambli; 2008, 2009; Vijayan et al., 1997). Each of these component traits, in turn, is controlled by several genes, their interaction among themselves and with the environment. For instance, under drought conditions, the association between leaf yield and its component traits vary significantly (Susheelamma et al., 1998).

Naturally occurring salt affected soils cover more than a billion hectors (Flowers and Flowers, 2005) and out of the 275 million hectors of the agricultural lands $20 \%$ is affected by salinization (Ghassemi et al., 1995). The most economic and viable method of utilizing the salt affected land is by developing salt tolerant crops to cultivate there. Developing salt tolerant crop, however, is not easy as salt tolerance is a complex trait contributed by several associated traits. In order to develop salt tolerant varieties integration of knowledge on physiological, biochemical and genetic aspects of salt tolerance is essential (Ashraf and Foolad, 2007). High concentration of $\mathrm{Na}^{+}$in the soil inhibits the growth of most of the glycophytes, which include most of the crop plants including mulberry (Jaleel 2007, 2009). Thus, in order to distinguish the salt tolerant from the salt sensitive and to develop salt tolerant varieties, it is important to have adequate knowledge on the interrelationship of various characters in the plant under salt stress conditions because the selection indices varies under stress and non-stress conditions (Gholipouri et al., 2009). Therefore, information on the impact of salt stress on interrelationships of leaf yield and its component traits will be of much help to formulate appropriate breeding and selection strategies in mulberry. Since, India, China, and other sericulturally important countries have vast areas affected by salinity especially in the arid and semiarid regions, evolution of salt tolerant mulberry varieties are seen to be an essential part of the ongoing research. Although studies in other crops like barley (Kumar and Gupta, 1984), tef (Asfwa and Itanna, 2009) and wheat (El-Hendawy et al., 2009; Sinclair and Hoffmann, 2003) have shown that the magnitude of association among traits associated with plant growth and developments vary significantly under different growing conditions. Unfortunately, there is a fundamental gap in our understanding on the relationship between tolerance at low and high salinity levels in mulberry. This is an important problem while choosing the salinity level that will be used for screening the plants because the physiological mechanisms that prevent damage at low salt concentrations are not the same as those that contribute to tolerance at extremely high concentrations. Keeping this in view, the present investigation was undertaken with an objective to work out the interrelationships among different traits including morphological, biochemical and anatomical characters under different salinity levels. 


\section{Materials and Methods}

Eleven mulberry genotypes comprising five parents such as English black, Rotundiloba, Mandalaya, Tollygunj, and C776 along with six hybrids developed from these parental genotypes were cultured under five different salinity levels viz., EC 1.6, 6.5, 10.1, 14.1 and $19.2 \mathrm{dSm}^{-1}$ respectively, developed via addition of $0.0 \%, 0.25 \%, 0.50 \%, 0.75 \%$ and $1.00 \%$ $\mathrm{NaCl}$ as described earlier (Vijayan et al., 2008a). Morphological traits such as number of branches, shoot height, leaf size, leaf fresh weight, leaf dry weight, moisture (\%), number of nodes per branches, root length, shoot fresh weight, shoot dry weight, root fresh weight, root dry weight and root-shoot ratio were recorded by planting three months old saplings on earthen pots as described earlier (Vijayan et al., 2008a,b). Biochemical assays for protein, soluble sugar, proline, phenol, nitrogen reductase (NRase), chlorophyll-a, chlorophyll-b, carotenoids, total chlorophyll, $\mathrm{K}^{+}: \mathrm{Na}^{+}$ ratio, and $\mathrm{Na}^{+}$and $\mathrm{K}^{+}$contents were conducted as described earlier (Vijayan et al., 2008a). The photosynthesis related characters such as photosynthetic rate, internal $\mathrm{CO}_{2}$ concentration, transpiration rate and physiological water use efficiency (WUE) were studied on $60^{\text {th }}$ day using LICOR 6200 portable photosynthetic meter (LI-COR Biosciences GmbH, Siemensstrasse 25A, D-61352 Bad Homburg, Germany). Fifth leaves from the apical portion of twigs were used for measurements as reported earlier (Das et al., 1999). Statistical analyses were carried out in SPSS/PC+ 10.0 program (M.J. Norusis, SPSS Inc., Chicago).

\section{Results and Discussion}

The association of different characters with the principle trait i.e., leaf as assessed by their correlation coefficients clearly suggest that the intensity of the association among these traits changes with the severity of the salt stress (Table 1). Under normal cultural conditions (control set in this case), the leaf yield was seen positively and significantly correlated with leaf size, root length, shoot length, and shoot fresh and dry weights. Although, the number of branches showed positive correlation but it was not significant which was in contradiction to some of the earlier observations that number of braches in mulberry is significantly correlated with leaf yield (Sahu et al., 1995; Vijayan et al., 1997). This could be due to the immaturity of the plant which was used for current observations as in general mulberry needs at least three to four years for better establishment and proper expression of characters. Recently, Tikader and Kamble (2008) observed almost similar results in an experiment with 25 germplasm accessions. They also found a positive but non-significant correlation between the number of branches and the leaf yield. However, leaf size and shoot lengths were highly correlated with leaf yield that agreed with most of the earlier observations (Tikader and Kamble; 2008, 2009; Vijayan et al., 1997). Under mild salinity imposed by $0.25 \%$ of $\mathrm{NaCl}$, number of branches, leaf size, root length, shoot length and shoot weight were highly positively correlated with leaf yield. But under severe salt stress imposed by $1.00 \%$ $\mathrm{NaCl}$, leaf size, leaf weight, root length, shoot length, root weight and shoot weight were positively and significantly associated with leaf yield. This clearly points to the fact that while selecting for salt tolerance, emphasis need to be give to root and shoot lengths. Some traits like moisture content showed negative correlations but none of them was found significant. The plant height also showed significant changes in its relationship with other component characters. Under normal condition only a few traits such as leaf dry weight, and root dry weight showed significant correlation with shoot height. But under high salinity almost all the morphological traits studied showed significant correlation (Table 2). In an earlier study under drought stress, 
Susheelamma et al. (1998) also found similar type of changes in the correlation of leaf yield with the plant height. However, this is the first attempt in mulberry to investigate the correlation between leaf yield and its component characters under salt stress conditions. Studies in other crops also revealed such changes under severe salinity (El-Hendawy et al., 2009; Kumar and Gupta, 1984). For example, correlation and path coefficient studies on 15 varieties of barley on saline and normal conditions revealed that yield was strongly correlated with number of tillers, 100 grain weight on normal conditions and germination and number of tillers in saline (Kumar and Gupta, 1984). Similarly, Gholipouri et al. (2009) and Sanjeri et al. (2006) also found significant changes in the character association in wheat under stress and non-stress conditions.

Table 1. Correlation coefficient of the principal trait "leaf yield" with its component traits of morphological, biochemical and photosynthetic characters in mulberry under different salinity levels.

\begin{tabular}{|c|c|c|c|c|c|}
\hline \multirow{2}{*}{ Characters } & \multicolumn{5}{|c|}{$\mathrm{NaCl}(\%)$} \\
\hline & 0.00 & 0.25 & 0.50 & 0.75 & 1.00 \\
\hline No. of branches & 0.236 & $0.483 * *$ & 0.278 & 0.236 & 0.189 \\
\hline Leaf size & $0.475 * *$ & $0.566^{* *}$ & 0.336 & $0.414 *$ & $0.390 *$ \\
\hline Leaf fresh Weight & -0.007 & 0.227 & $0.359 *$ & $0.449 * *$ & $0.674 * *$ \\
\hline Leaf dry weight & -0.028 & 0.237 & $0.463 * *$ & $0.485 * *$ & $0.696 * *$ \\
\hline Moisture (\%) & 0.004 & -0.083 & -0.244 & 0.010 & -0.211 \\
\hline No. of nodes & -0.138 & -0.047 & -0.113 & 0.086 & $0.370^{*}$ \\
\hline Root length & $0.480 * *$ & $0.414 *$ & $0.576^{* *}$ & $0.570 * *$ & $0.589 * *$ \\
\hline Shoot length & $0.453 * *$ & $0.617 * *$ & $0.608 * *$ & 0.329 & $0.517 * *$ \\
\hline Shoot fresh weight & $0.822 * *$ & $0.808 * *$ & $0.694 * *$ & $0.638 * *$ & $0.739 * *$ \\
\hline Shoot dry weight & $0.734 * *$ & $0.804 * *$ & $0.692 * *$ & $0.570 * *$ & $0.761 * *$ \\
\hline Root fresh weight & 0.245 & 0.252 & $0.531 * *$ & $0531 * *$ & $0.594 * *$ \\
\hline Root dry weight & 0.245 & 0.316 & $0.622 * *$ & $0.601 * *$ & $0.659 * *$ \\
\hline Root-shoot ratio & -0.257 & -0.302 & -0.046 & 0.064 & 0.178 \\
\hline Protein & $0.441 * *$ & 0.333 & $0.396^{*}$ & 0.301 & $0.381 *$ \\
\hline Sugar & -0.123 & 0.077 & 0.227 & $0.353^{*}$ & 0.147 \\
\hline Proline & -0.289 & 0.182 & -0.150 & -0.102 & 0.198 \\
\hline Phenol & -0.303 & -0.285 & $-0.368 *$ & 0.100 & 0.034 \\
\hline NRase & 0.162 & 0.203 & $0.364^{*}$ & $0.536 * *$ & 0.124 \\
\hline Chlorophyll-a & -0.094 & 0.280 & 0.126 & 0.074 & $0.373^{*}$ \\
\hline Chlorophyll-b & -0.079 & 0.263 & -0.178 & 0.001 & 0.192 \\
\hline Carotenoids & -0.283 & 0.271 & 0.176 & 0.236 & $0.564 * *$ \\
\hline Total chlorophyll & -0.123 & 0.319 & 0.045 & 0.057 & 0.326 \\
\hline $\mathrm{K}^{+}: \mathrm{Na}^{+}$ratio & -0.081 & 0.255 & 0.173 & 0.272 & $0.486 * *$ \\
\hline $\mathrm{Na}^{+}$ & 0.010 & -0.208 & -0.141 & -0.332 & $-0.345^{*}$ \\
\hline $\mathbf{K}^{+}$ & -0.031 & 0.108 & 0.064 & 0.019 & $0.373^{*}$ \\
\hline Photosynthetic rate & $0.366^{*}$ & $0.551 * *$ & $0.463 * *$ & $0.434 *$ & $0.503 * *$ \\
\hline Internal $\mathrm{CO}_{2}$ & -0.235 & -0.217 & -0.257 & $-0.407^{*}$ & -0.191 \\
\hline Stomatal Cond. & -0.066 & -0.123 & -0.227 & -0.143 & 0.038 \\
\hline Transpiration & -0.314 & 0.074 & -0.011 & 0.124 & 0.032 \\
\hline \multirow{2}{*}{ WEU } & 0.318 & $0.552 * *$ & $0.493 * *$ & $0.423 *$ & 0.028 \\
\hline & $\mathrm{n}=33$ & $\mathrm{n}=33$ & $\mathrm{n}=33$ & $n=33$ & $\mathrm{n}=33$ \\
\hline
\end{tabular}

Significance ${ }^{*} \mathrm{p}<0.05,{ }^{* *} \mathrm{p}<0.01$ 
Emir. J. Food Agric. 2010. 22 (4): 318-325

http://ffa.uaeu.ac.ae/ejfa.shtml

Table 2. Correlation coefficient of shoot height with other morphological, biochemical and photosynthetic characters in mulberry under different salinity levels.

\begin{tabular}{|c|c|c|c|c|c|}
\hline \multirow{2}{*}{ Characters } & \multicolumn{5}{|c|}{$\mathrm{NaCl}(\%)$} \\
\hline & 0.00 & 0.25 & 0.50 & 0.75 & 1.00 \\
\hline No. of branches & 0.202 & 0.074 & 0.012 & $0.400^{*}$ & 0.251 \\
\hline Leaf size & 0.018 & 0.182 & 0.088 & 0.288 & 0.314 \\
\hline Leaf fresh Weight & -0.330 & 0.213 & 0.151 & 0.086 & 0.319 \\
\hline Leaf dry weight & $-0.344 *$ & 0.191 & 0.175 & 0.027 & $0.355^{*}$ \\
\hline Moisture (\%) & 0.287 & 0.025 & -0.017 & 0.273 & -0.254 \\
\hline No. of nodes & $0.343^{*}$ & 0.088 & 0.007 & $0.513 * *$ & $0.556 * *$ \\
\hline Root length & 0.067 & $0.458 * *$ & $0.712 * *$ & $0.696^{* *}$ & $0.389^{*}$ \\
\hline Shoot fresh weight & $0.409^{*}$ & $0.585^{* *}$ & $0.671^{* *}$ & $0.414^{*}$ & $0.638^{* *}$ \\
\hline Shoot dry weight & 0.221 & $0.376^{*}$ & $0.707 * *$ & $0.403^{*}$ & $0.594 * *$ \\
\hline Root fresh weight & 0.086 & $0.458 * *$ & $0.744 * *$ & $0.492 * *$ & $0.574 * *$ \\
\hline Root dry weight & $0.453 * *$ & $0.617 * *$ & $0.608 * *$ & $0.329^{*}$ & $0.517 * *$ \\
\hline Root-shoot ratio & -0.245 & -0.022 & 0.063 & 0.071 & -0.105 \\
\hline Proteins & 0.035 & 0.085 & 0.294 & $0.516 * *$ & $0.541 * *$ \\
\hline Sugar & 0.029 & -0.067 & 0.087 & 0.221 & $0.461 * *$ \\
\hline Proline & -0.148 & -0.068 & -0.183 & -0.059 & -0.141 \\
\hline Phenol & -0.077 & 0.123 & -0.184 & 0.138 & $0.462 * *$ \\
\hline NRase & -0.115 & 0.099 & 0.302 & $0.441 * *$ & $0.475^{* *}$ \\
\hline Chlorophyll-a & 0.255 & 0.228 & 0.145 & $0.436^{*}$ & $0.455^{* *}$ \\
\hline Chlorophyll-b & 0.082 & 0.231 & 0.039 & $0.449 * *$ & $0.430^{*}$ \\
\hline Carotenoids & 0.145 & $0.379^{*}$ & 0.196 & $0.440 * *$ & $0.559 * *$ \\
\hline Total chlorophyll & 0.119 & 0.264 & 0.103 & $0.502 * *$ & $0.481 * *$ \\
\hline $\mathrm{K}^{+}: \mathrm{Na}^{+}$ratio & -0.190 & 0.134 & 0.258 & $0.447 * *$ & $0.459 * *$ \\
\hline $\mathbf{N a}^{+}$ & 0.103 & -0.030 & 0.116 & $-0.528 * *$ & $-0.522 * *$ \\
\hline $\mathbf{K}^{+}$ & 0.094 & 0.197 & 0.168 & 0.060 & 0.243 \\
\hline Photosynthetic rate & 0.029 & $0.491 * *$ & 0.194 & $0.431 *$ & $0.383^{*}$ \\
\hline Internal $\mathrm{CO}_{2}$ & -0.208 & -0.157 & 0.053 & -0.233 & -0.316 \\
\hline Stomatal Cond. & -0.269 & -0.130 & -0.262 & 0.090 & 0.239 \\
\hline Transpiration & -0.233 & 0.213 & $0.352^{*}$ & 0.132 & 0.225 \\
\hline \multirow[t]{2}{*}{ WEU } & 0.035 & 0.228 & 0.218 & 0.244 & 0.222 \\
\hline & $\mathrm{n}=33$ & $\mathrm{n}=33$ & $\mathrm{n}=33$ & $\mathrm{n}=33$ & $\mathrm{n}=33$ \\
\hline
\end{tabular}

Significance $* \mathrm{P}<0.05, * * \mathrm{p}<0.01$

Regarding the correlation of biochemical parameters with leaf yield, under normal salt level only proteins showed significantly positive correlation with leaf while other traits showed negative correlations with leaf yield (Table 1). However, under salt stress conditions, proteins, chlorophyll-a, total chlorophyll contents in the leaf showed significantly positive correlations. Proline, NRase and $\mathrm{Na}^{+}$showed significantly negative correlations. The photosynthetic rate was significantly and positively correlated with leaf yield in all the cultural conditions. Under high salt stress, water use efficiency and transpiration rates showed significantly positive correlation with leaf yield. Thus, it is clear that under slat stress condition the character association in mulberry differed significantly from that under normal conditions. Susheelamma et al. (1998) also found similar type of changes in the correlation of leaf under drought stress.

Biochemical characters also showed significant correlation with leaf yield (Table 1). Under normal condition the leaf was positively significantly correlated with soluble proteins. Soluble sugar, on the other hand, showed negative correlation in 
the normal condition but showed positive correlation under higher saline conditions. Proline did not show any significance with the leaf yield except under $1.00 \% \mathrm{NaCl}$ where it exhibited a negative correlation. NRase showed positive correlation with leaf yield. Though chlorophyll-a was positively correlated with leaf yield, the other two pigments did not show much correlation with the leaf yield. Concentrations of sodium showed negative correlation with the leaf yield. The detrimental effects of high concentration of $\mathrm{Na}^{+}$in the soil on growth, leaf morphology and biochemical components have been well documented (Koyro, 2000). The toxicity of $\mathrm{Na}^{+}$in plants is caused by osmotic stress, enzyme inhibition and competition with $\mathrm{K}^{+}$(Tester and Davenport, 2003).

Photosynthetic rate showed a very strong positive correlation with the leaf yield. The other three parameters i.e., internal $\mathrm{CO}_{2}$ concentration, stomatal conductance and transpiration rate did not show any significant correlation with the leaf yield except that of water use efficiency, which had a very strong positive correlation with the leaf yield. Similar type of strong correlation between WUE and yield was observed in barley (Febrero et al., 1994). Likewise, photosynthetic rate was positively correlated with the shoot dry weight of cotton (Brugnoli and Lauteri, 1990). A reduced photosynthetic rate is the general observation in plants, which could be due to the result of stomatal closure or more directly through the toxic effect of salinity on the photosynthetic apparatus (Praxedes et al., 2009). In an earlier experiment, Lakshmi et al. (1996) reported significant reduction in photosynthesis due to reduced stomatal conductance $\left(g_{\mathrm{s}}\right)$ in mulberry under salinity, this reports completely agrees with the findings in the present study.

Thus, from the present study it can be concluded that interrelationship among the important leaf yield contributing traits changes under different stress conditions. This necessitates changes in the selection criteria for mulberry breeding under low and high salt concentrations.

\section{References}

Asfwa, K. G. and Itanna, F. 2009. Screening some Tef (Eragrostis tef (Zucc.) Trotter) accessions/verities fro salt tolerance during germination and seedling growth. MEJS 1 (2):17-29.

Ashraf, M. and M. R. Foolad. 2007. Roles of glycine betaine and proline in improving plant abiotic stress resistance. Environ. Exp. Bot. 59:206-216.

Banerjee, R., S. Roychowdhuri, H. Sau, B. K. Das, P. Ghosh and B. Saratchandra. 2007. Genetic diversity and Interrelationship among mulberry genotypes. J. Gene. Genom. 34:691697

Brugnoli, E. and M. Lauteri. 1990. Effects of salinity on stomatal conductance, photosynthetic capacity, and carbon isotope discrimination of salt-tolerant (Gossipium hirsutum L.) and salt sensitive (Phaseolus vulgaris L.) C3 Non-halophytes. Plant Physiol. 95:628-635.

Das, C. T. Sengupta, P. K. Sahu, A. K. Misra, S. K. Sen and B. Saratchandra. 1999. Quantitative analysis of photosynthetic parameters in mulberry leaf. Indian J. Plant Physiol. 4:171-174.

El-Hendawy, S. E., Y. Ruan, Y. Hu, and U. Schmidhalter. 2009. A comparison of screening criteria for salt tolerance in wheat under field and controlled environmental conditions. J. Agron. Crop Sci.195(5):356-367. 
Febrero, A., J. Bort, J. Catala, P. Marzabal, J. Voltas and J. L. Araus. 1994. Grain yield, carbon isotope discrimination and mineral content in mature kernels of barley under irrigated and rainfed conditions. Agron. 14(2):127-132.

Flowers, T. J and S. A. Flowers. 2005. Why does salinity pose such a difficult problem for plant breeders? Agrl. Water Manag. 78:15-24.

Ghassemi, F., A. J. Jakeman and H. A. Nix. 1995. Salinisation of land and water resources. Human causes, extent, management and case studies. University of New South Wales, Sydney. pp.256.

Gholipouri, A., M. Sedghi, R. S. Sharifi, N. M. Nazari. 2009. Evaluation of drought tolerance indices and their relationship with grain yield in wheat cultivars. Recent. Res. Sci. Tech. 1(4):195-198.

Jaleel, C. A., R. Gopi, P. Manivannan and R. Panneerselvam 2007. Responses of antioxidant defense system of Catharanthus roseus (L.) G. Don. to paclobutrazol treatment under salinity. Act. Physiol. Plant. 29:205209.

Jaleel, C. A. and M. M. Azooz. 2009. Exogenous calcium alters pigment composition, $\gamma$-glutamyl kinase and proline oxidase activities in salt stressed Withania somnifera. Plant Omics J. 2(2):85-90.

Kumar, D. and S. C. Gupta. 1984. Correlation and path-coefficient analysis in barley grown on normal and saline soils. Indian J. Agril. Sci. 54:356-358.

Koyro, H. W. 2000. Effect of NaCl-salinity on plant growth, leaf morphology and ion composition in leaf tissues of Beta vulgaris spp. maritima. J. Appl. Bot. 74: 67-73.

Lakshmi, A., S. Ramanjulu, K. Veeranjaneylu and C. Sudhakar. 1996. Effect of $\mathrm{NaCl}$ on photosynthesis parameters in two cultivars of mulberry. Photosynthetica 32: 285-289.

Praxedes, S. C., C. F. de Lacerda, F. M. DaMatta, J. T. Prisco and E. GomesFilho. 2009. Salt tolerance is associated with differences in ion accumulation, biomass allocation and photosynthesis in cow pea cultivars. J. Agron. Crop. Sci. DOI. 10.1111/j.1439-037X.2009-00412.x

Sahu, P. K., B. R. D. Yadav and B. Saratchandra. 1995. Evaluation of yield components in mulberry germplasm varieties. Acta Bot. 23:191-197.

Sanjeri, A., M. valizadeh, A. Majidi and M. R. Shiri. 2006. Evaluation of new bread wheat genotype under different drought stress conditions for grain yield and some important agronomic and physiologic charcters. J. Agrl. Sci. 16(3):97-112.

Sinclair, S. and A. A. Hoffmann. 2009. Developmental Stability as a Potential Tool in the Early Detection of Salinity Stress in Wheat. Int. J Plant Sci. 164:325-331.

Susheelamma, B. N., M. S. Jolly, K. Giridhar, N. K. Dwivedi and N. Suryanarayana. 1998. Correlation and path-analysis in mulberry under stress conditions. Sericol. 28:239-243.

Tester, M. and R. Davenport. 2003. Na+ tolerance and $\mathrm{Na}+$ transport in higher plants. Ann. Bot. 91:503-527. 
Tikader, A. and C. K. Kamble. 2008. Studies on Variability of Indigenous Mulberry Germplasm on Growth and Leaf Yield. Pertanika J. Trop. Agric. Sci. 31:163-170.

Tikader, A. and C. K. Kamble. 2009 Development of core collection for perennial mulberry (Morus spp.) germplasm. Pertanika J. Sci. Tech. $17: 43-51$.

Vijayan, K., A. Tikader, K. K. Das, S. P. Chakraborti and B. N. Roy. 1997. Correlation studies in mulberry (Morus spp.). Indian J. Genet. Breed. 57:455-460.
Vijayan, K, S. P. Chakraborti, S. G. Doss, P. D. Ghosh and S. Ercisli. 2008a. Combining ability for morphological and biochemical characters in mulberry (Morus spp.) under salinity stress. International J. Indust. Entomol. 16:67-74.

Vijayan, K., S. P. Chakraborti, S. Ercisli and P. D. Ghosh. 2008b. NaClinduced morpho-biochemical and anatomical changes in mulberry (Morus spp.). Plant Growth Regul. 56:61-69.

Vijayan, K. 2009. Approaches for enhancing salt tolerance in mulberry (Morus L) -A review. Plant Omics J. 2(1):41-59. 